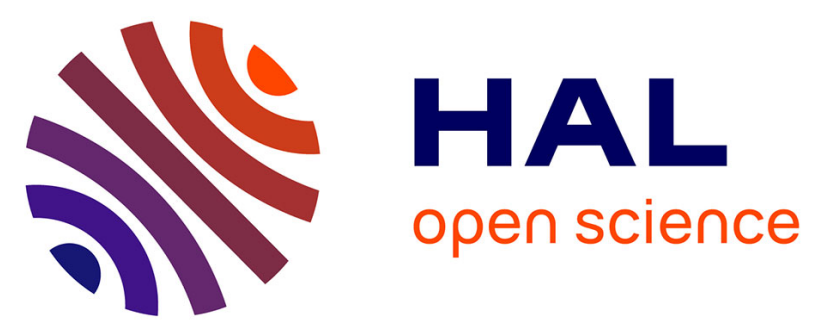

\title{
Structure-Based Design, Synthesis, and Characterization of the First Irreversible Inhibitor of Focal Adhesion Kinase
}

Expédite Yen-Pon, Bo Li, Marta Acebrón-Garcia-De-Eulate, Céline Tomkiewicz-Raulet, John Dawson, Daniel Lietha, Margaret C. Frame, Xavier

Coumoul, Christiane Garbay, Mélanie Etheve-Quelquejeu, et al.

\section{To cite this version:}

Expédite Yen-Pon, Bo Li, Marta Acebrón-Garcia-De-Eulate, Céline Tomkiewicz-Raulet, John Dawson, et al.. Structure-Based Design, Synthesis, and Characterization of the First Irreversible Inhibitor of Focal Adhesion Kinase. ACS Chemical Biology, 2018, 13 (8), pp.2067-2073. 10.1021/acschembio.8b00250 . hal-02196326

\section{HAL Id: hal-02196326 \\ https://hal.science/hal-02196326}

Submitted on 27 Jul 2019

HAL is a multi-disciplinary open access archive for the deposit and dissemination of scientific research documents, whether they are published or not. The documents may come from teaching and research institutions in France or abroad, or from public or private research centers.
L'archive ouverte pluridisciplinaire HAL, est destinée au dépôt et à la diffusion de documents scientifiques de niveau recherche, publiés ou non, émanant des établissements d'enseignement et de recherche français ou étrangers, des laboratoires publics ou privés. 


\title{
Structure-based design, synthesis and characterization of the first irreversible inhibitor of Focal Adhesion Kinase
}

\author{
Expédite Yen-Pon, ${ }^{\dagger, \ddagger}$ Bo Li, ${ }^{\dagger \dagger}$ Marta Acebrón-Garcia de Eulate, $\|$ Céline Tomkiewicz-Raulet, ${ }^{\S}$ \\ John Dawson, ${ }^{\perp}$ Daniel Lietha,॥ Margaret C. Frame, ${ }^{\perp}$ Xavier Coumoul, ${ }^{\S}$ Christiane Garbay, ${ }^{\dagger}$ \\ Mélanie Etheve-Quelquejeu, ${ }^{\dagger}$ Huixiong Chen ${ }^{\dagger, *}$ \\ ${ }^{\dagger}$ Chemistry of RNA, nucleosides, peptides and heterocycles, CNRS UMR8601, Université Paris Descartes,
PRES Sorbonne Paris Cité, UFR Biomédicale, 45 rue des Saints-Pères, 75270 Paris Cedex 06, France
} "Cell Signalling and Adhesion Group, Structural Biology Programme, Spanish National Cancer Research Centre (CNIO), Calle Melchor Fernández Almagro 3, Madrid 28029, Spain

${ }^{\S}$ Toxicologie, Pharmacologie et Signalisation Cellulaire, INSERM, UMR S 1124, Université Paris Descartes, PRES Sorbonne Paris Cité, UFR Biomédicale, 45 rue des Saints-Pères, 75270 Paris Cedex 06, France

${ }^{\perp}$ Edinburgh Cancer Research UK Centre, Institute of Genetics and Molecular Medicine, University of Edinburgh, Edinburgh EH4 2XR, UK

\begin{abstract}
Focal Adhesion Kinase signaling pathway and its functions have been involved in the development and aggressiveness of tumor malignancy, it then presents a promising cancer therapeutic target. Several reversible FAK inhibitors have been developed and are being tested in clinical trials. On the other hand, irreversible covalent inhibitors would bring many desirable pharmacological features including high potency and increased duration of action. Herein, we report the structure-guided development of the first highly potent and irreversible inhibitor of FAK. This inhibitor showed a very potent decreased autophosphorylation of FAK in squamous cell carcinoma. A cocrystal structure of the kinase domain in complex with this compound revealed its binding mode within the ATP binding site and confirmed the covalent linkage between the targeted Cys427 of the protein and the inhibitor.
\end{abstract}

Focal adhesion kinase (FAK) is an ubiquitously expressed non-receptor protein tyrosine kinase and a scaffold protein localized to focal adhesions, which plays important roles in many biological process including survival, proliferation, angiogenesis, adhesion, motility, metastasis, tumor microenvironment, epithelial to mesenchymal transition (EMT) as well as cancer stem cell renewal. ${ }^{1-2}$ Furthermore, FAK has recently been shown to be localized in the nucleus and could promote survival and cell proliferation by interacting directly with p53. ${ }^{9}$ 
FAK inhibition could also trigger immune-mediated tumor regression through the control of regulatory T-cell (Treg) in the tumor environment. ${ }^{10} \mathrm{FAK}$ is also over-expressed in a variety of solid and non-solid tumors, which make it a promising therapeutic target. ${ }^{3-4}$ In recent years, numerous clinical trials have been developed with small FAK inhibitor molecules..$^{5-6}$ The results of such inhibitors are interesting since the decrease of tumor growth and metastasis development was observed in some preclinical models and in cancer patients, even if some adverse events have been revealed. ${ }^{7}$ In order to enhance the efficacy of anti-FAK cancer treatments, the trials are conducted either individually or in combination. Recent advances in the evaluation of FAK inhibitors in preclinical and clinical models are very promising..$^{7-8}$ Moreover, the development of covalent irreversible inhibitors to target kinases have recently garnered significant interest. ${ }^{11-12}$ From a therapeutic point of view, the main advantages of irreversible inhibitors are i) an increase of the target residence time to obtain durable inhibition without maintaining continuous drug exposure; ii) a better ability to avoid drug resistance by reducing the development of resistance mutations. ${ }^{13}$ Although there is only very few of irreversible tyrosine kinase inhibitors used as therapeutic agents in the fields of oncology nowadays, the number of these new inhibitors is steadily increasing to enter clinical trials.

\section{RESULTS AND DISCUSSION}

Design of Irreversible Covalent Inhibitors. In order to assess the feasibility of designing irreversible inhibitors of FAK, our strategy entailed identifying a suitable cysteine residue within or next to the ATP binding pocket. This approach would be amenable by using a kinome-wide sequence analysis in connection with 3D structure of the ATP site. In particular, we noticed that FAK contains a cysteine residue in the Glycine-rich loop region closer to the ATP site, a feature which is not observed in most of other human kinases (Figure 1A). The distance between Cys427 and a reversible inhibitor, such as TAE226 (PDB ID: $2 J K K)^{14}$ or PHM16 (PDB ID: 4BRX) ${ }^{15}$ in the ATP binding site is less than $10 \AA$ (Figure 1B).

Based on the two-step process for kinase inhibition, we designed our inhibitors, which first bind reversibly to the enzyme, forming a non-covalent complex, and then form a covalent binding with the residue Cys427 of the enzyme to provide an irreversible complex (Figure S1, equation 1). Pyrimidine derivatives, especially 2,4-dianilinopyrimidine derivatives, are one of the important scaffolds found in many compounds described by pharmaceutical companies and academic laboratories. ${ }^{6,16-18}$ These pyrimidine-containing inhibitors efficiently target the 
FAK scaffolding function and suppress tumor growth through inhibition of Akt signaling or activation of p53 signaling and its downstream targets. ${ }^{10}$ Our design strategy required the synthesis of 2,4-pyrimidine derivatives as a scaffold to maintain affinity similar to reversible inhibitors (compound 2, Figure 1C), and inclusion of a linker with Michael acceptor which could react with the nucleophilic Cys427 residue. A number of diverse linkers were evaluated, we quickly focused upon two linkers, a squarate (3,4-bisaminocyclobutane-1,2-dione) (5 and 6) and a 1,2,3-triazole ( $\mathbf{7}$ and $\mathbf{8}$ ) motif which are able to sustain a good orientation to target Cys427 in the Glycine-rich loop region of the FAK kinase. Concerning the electrophile motif, an acrylate group was chosen to maintain reactivity $(\mathbf{5}, \mathbf{7}$ and $\mathbf{8}$ in Figure 1C).
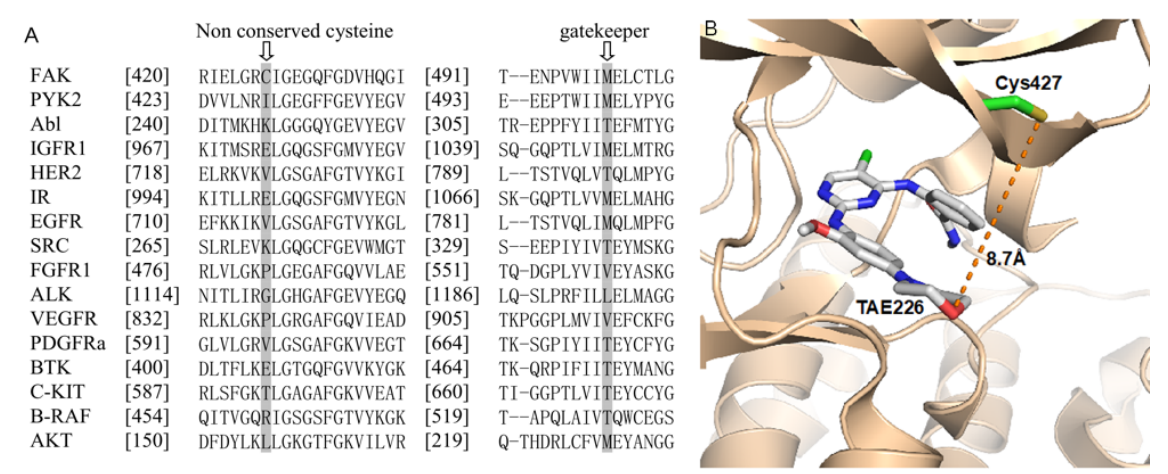
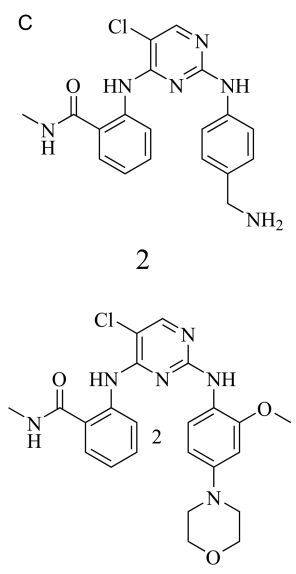

TAE226

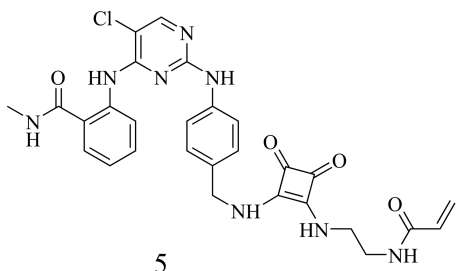<smiles>C/C=C\C(=O)NC</smiles>

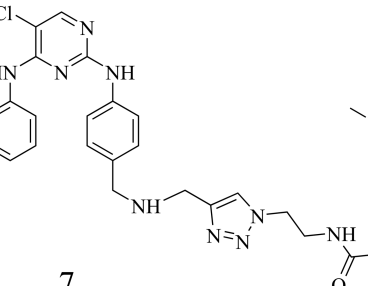

7
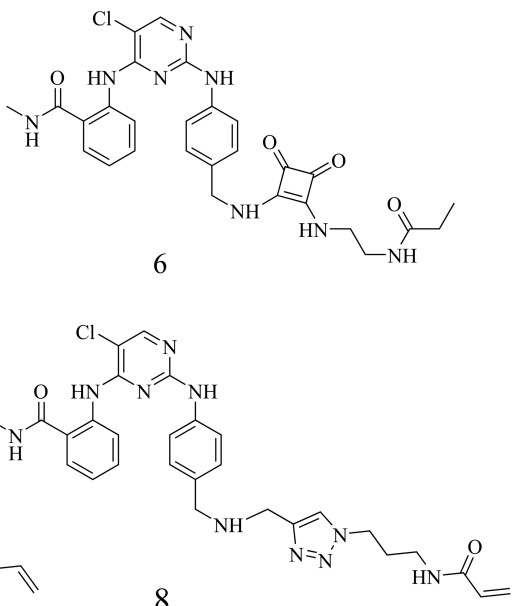

Figure 1. Design of a potent and electrophilic inhibitor of FAK guided by structural bioinformatics. (A) Partial sequence alignment of FAK with 15 other protein kinases, (B) Structural assessment of cysteine residue 427 for covalent binding to FAK. The structure shows the FAK kinase (tan ribbon) bound to TAE226 (white sticks) (PDB ID: 2JKK). The Cys427 side chain is colored in green and its distance to TAE226 indicated. (C) Reversible and irreversible inhibitors of FAK. 
Synthesis of FAK Inhibitors. The synthetic route of new 2,4-pyrimidine compounds is outlined in Scheme 1 (for compounds 5 and 6) and Scheme S1 (for compounds 7 and 8). Starting from commercially available 2,4,5-trichloropyrimidine, the first chlorine atom in position 4 of 2,4,5-trichloropyrimidine is displaced by 2-amino- $\mathrm{N}$-methylbenzamide in the presence of $\mathrm{NaHCO}_{3}$ in EtOH at reflux to afford monosubstituted intermediate in a yield of $93 \%$. This was further substituted to compound 1 in the presence of the corresponding $(9 \mathrm{H}-$ fluoren-9-yl)methyl(4-aminobenzyl)carbamate and $\mathrm{HCl}$ in $\mathrm{n}-\mathrm{BuOH}$ in a yield of $53 \%$. The amino protecting Fmoc group of $\mathbf{1}$ was removed using piperidine to provide the key intermediate 2 . Then, the electrophilic 1,4-addition reactions occurred between compound 1 and dimethyl squarate in the presence of DIPEA at room temperature to afford compound $\mathbf{3}$ in a yield of $81 \%$. This was further condensed with tert-butyl (2-aminoethyl)carbamate in the presence of DIPEA, followed by the deprotection of Boc group to give compound 4. Finally, acylation of the primary amine with acryloyl chloride or propionyl chloride gave the expected, targeted covalent inhibitor $\mathbf{5}$ and the corresponding reversible inhibitor $\mathbf{6}$, without the electrophilic warhead. Another potential irreversible inhibitors 7 and 8 bearing a 1,3,5-triazole linker were also synthesized in a similar manner (Scheme S1).

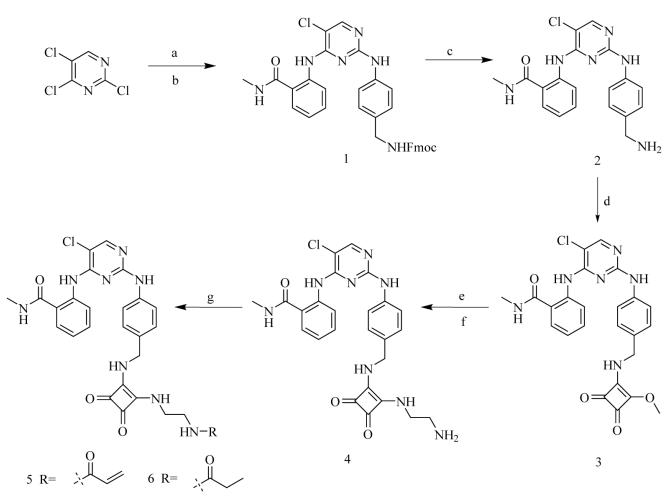

Scheme 1. Synthesis of FAK targeted covalent inhibitor $\mathbf{5}$ and reversible inhibitor matchedpair 6. Reagents and conditions: a) 2-amino-N-methylbenzamide, $\mathrm{NaHCO}_{3}$, EtOH, reflux; b) (9H-fluoren-9-yl)methyl (4-aminobenzyl)car-bamate, $\mathrm{HCl}, \mathrm{n}-\mathrm{BuOH}, 120{ }^{\circ} \mathrm{C}$; c) piperidine, DMF, RT; d) dimethyl squarate, DIPEA, DMF, RT; e) tert-butyl (2-aminoethyl)carbamate, DIPEA, DMF, $70{ }^{\circ} \mathrm{C}$; f) TFA, DCM, RT; g) Acryloyl chloride or propionyl chloride, $\mathrm{NEt}_{3}$, DMF, RT.

Biochemical Characterization of FAK Inhibitors. To establish whether our rationally designed targeted covalent inhibitors 5, 7 and $\mathbf{8}$ could form irreversible complexes, their inhibitory potency were first assessed using an ADP-Glo ${ }^{\mathrm{TM}}$ kinase assay. One previously 
reported inhibitor of FAK, TAE226, was used as a control. In this assay, TAE226 showed IC $_{50}$ value of $5.8 \mathrm{nM}$ against the kinase activity of FAK (Table 1), which was similar to previously reported data. ${ }^{19}$

Table 1. In Vitro Enzymatic Activities of Novel 2,4-diarylaminopyrimidines compared with TAE226

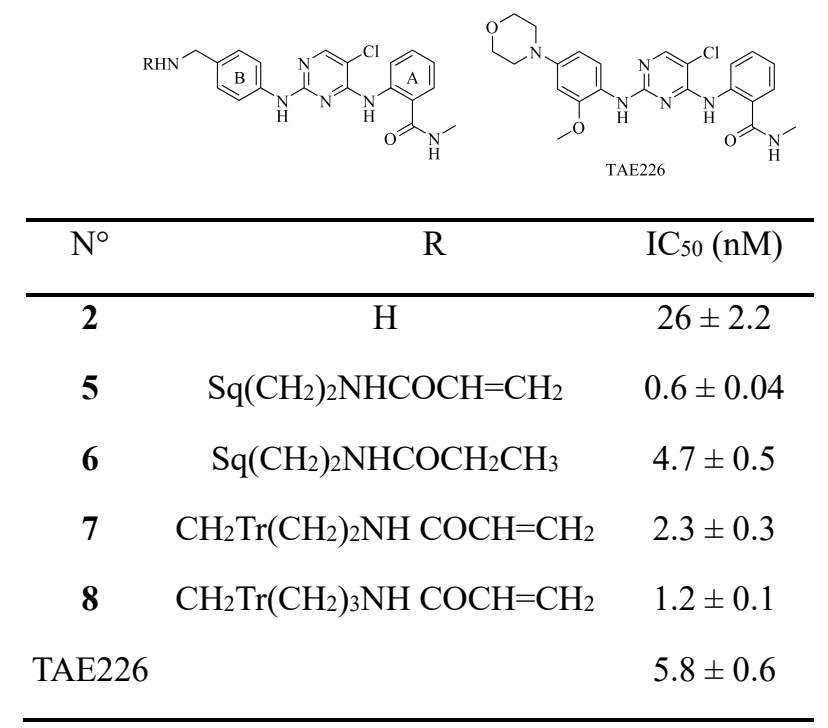

Sq: squaramide group; Tr: 1,2,3-triazole group

As expected, our selected 2,4-dianilinopyrimidine scaffold (compound 2) showed a potent inhibitory activity to FAK $\left(\mathrm{IC}_{50}=26 \mathrm{nM}\right)$, as shown in Table 1 . Interestingly, the introduction of different groups on the amine function of the benzylamino moiety (ring B) resulted in a very large increase in inhibitory potency on FAK kinase activity (compounds $\mathbf{5}, \mathbf{6}$, 7 and 8), showing specific contributions of these groups. Compounds bearing a 1,2,3-triazole group (7 and 8) gave an inhibitory potency of 2.3 and $1.2 \mathrm{nM}$, respectively, which are more potent than TAE226. Interestingly, compound 5 bearing a squarate group demonstrated the best inhibitory activity $\left(\mathrm{IC}_{50}=0.6 \mathrm{nM}\right)$, which was largely better than that of the matched pair 6, without a reactive acryloyl group $\left(\mathrm{IC}_{50}=4.7 \mathrm{nM}\right)$.

As irreversible inhibitors always increase inhibitory potency over time, we then investigated time-dependence inhibition of FAK kinase by the putative irreversible inhibitors 5, 7 and 8, as compared with the reversible matched pair 6. As shown in Figure 2, only compound 5 displayed an increase in its inhibitory potency over $2 \mathrm{~h}$, which was consistent with the formation of a covalent bond. As expected, the reversible matched pair $\mathbf{6}$ displayed 
no time-dependence. Unfortunately, the putative irreversible inhibitors of FAK $\mathbf{7}$ and $\mathbf{8}$ displayed no time-dependence in this assay.
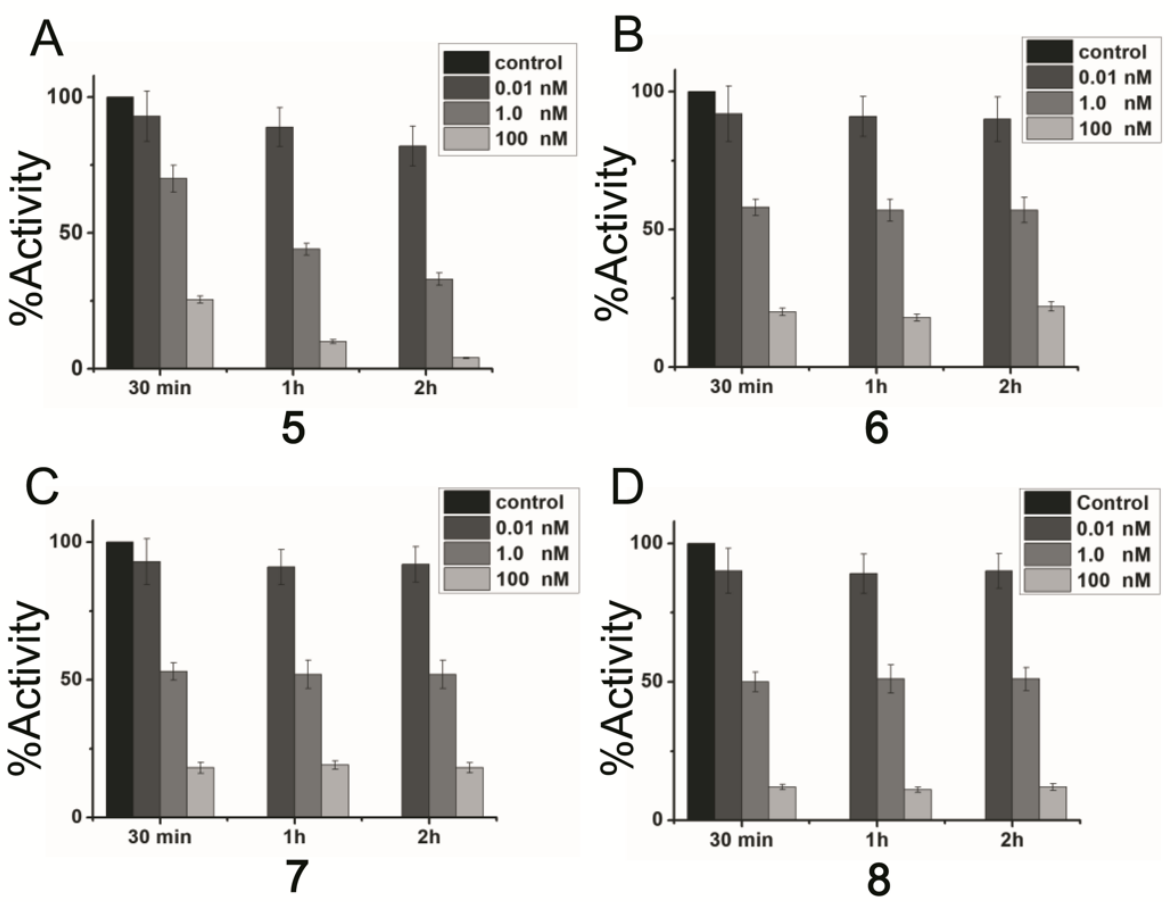

Figure 2. (A) Targeted covalent inhibitor $\mathbf{5}$ shows time-dependent inhibition of FAK kinase, (C-D) No time-dependent inhibition of FAK kinase with targeted reversible inhibitors $\mathbf{6 , 7 , 8 .}$

Since high intracellular ATP concentrations under physiological conditions influence the cellular potency of ATP-competitive inhibitors of protein kinases, non-ATP competitive inhibitors provide distinct advantages to conventional ATP-competitive binders. Thus, developing irreversible inhibitors is an attractive and alternative strategy to achieve the nonATP competitive inhibition of kinase-mediated signaling. Therefore, we studied noncompetitive character versus ATP of the putative irreversible inhibitor 5, compared with the reversible matched pair 6. Indeed, as shown in Figure 3, inhibitor 5 showed the same inhibition at the different concentrations of ATP. On the contrary, the inhibitory potency of the matched pair $\mathbf{6}$ on FAK kinase activity decreased with increasing concentration of ATP. 


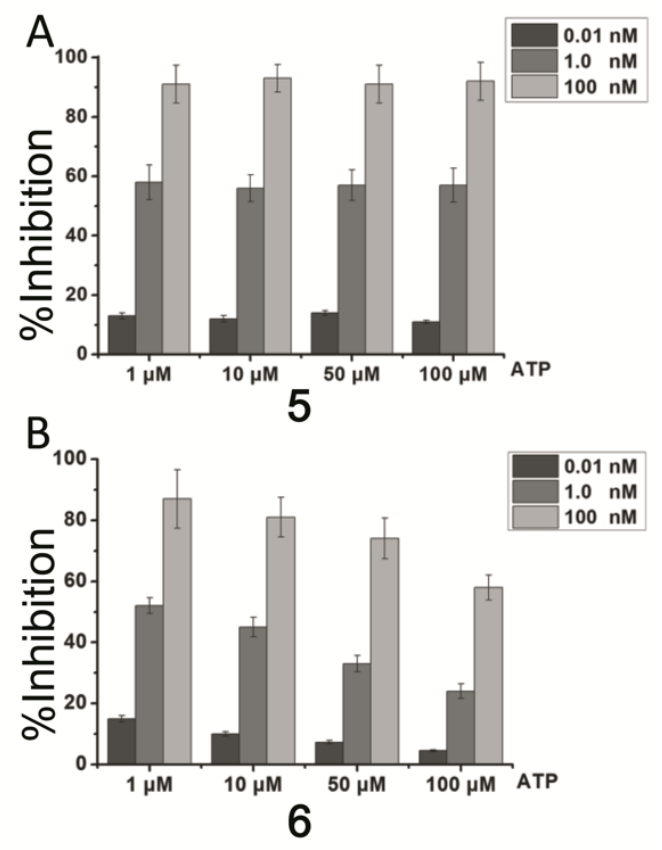

Figure 3. (A) Targeted covalent inhibitor 5 shows non-ATP dependent inhibition of FAK kinase, (B) ATP-dependent inhibition of FAK kinase with targeted reversible inhibitor 6.

Crystal Structure of FAK Bound to Inhibitors. To confirm the formation of a covalent bond and to verify that the binding mode of the bis-anilinopyrimidine part is similar to the reversible counterparts, we resolved the cocrystal structures of FAK kinase domain successively with compounds 5 (PDB ID: 6GCX), 6 (PDB ID: 6GCW) and 7 (PDB ID: 6GCR). As shown in Figures 4, the mode of interaction of these compounds with the FAK kinase domain is very similar to that observed in complex with TAE226 or PHM16. Indeed, our inhibitors stabilize an unusual helical conformation of the DFG motif (D564-F565-G566) in which the phi torsion angle of Asp564 is rotated by $113^{\circ}$, compared to the active kinase domain. Compounds 5, $\mathbf{6}$ and 7 contain a common 5-chloro-2-anilino-4-(2methylcarbamoyl)anilinopyrimidines scaffold, which binds well to the hinge region of the FAK kinase in an identical manner. Three hydrogen bonds are observed in the crystal structure of FAK bound to inhibitors. Among them, two are formed between the nitrogen in the pyrimidine and 2-aniline moieties with the backbone nitrogen and the carbonyl group of Cys502 in the kinase hinge (Figure 4A-C). Another one is formed between the $\mathrm{CO}$ of carboxamide group of our inhibitor and the backbone nitrogen of Asp564 of the DFG motif. Some of hydrophobic interactions are observed between the carbon atomes of the 2-aniline ring and Ile428 and Gly505, but also between carbons in the pyrimidine ring and Ala452 and 
Leu553. As already observed in the crystallographic structure of a complex between FAK and TAE226, The chlorine atom on the pyrimidine ring is located into the ATP binding pocket, near the gatekeeper residue Met499 (Figure S2).

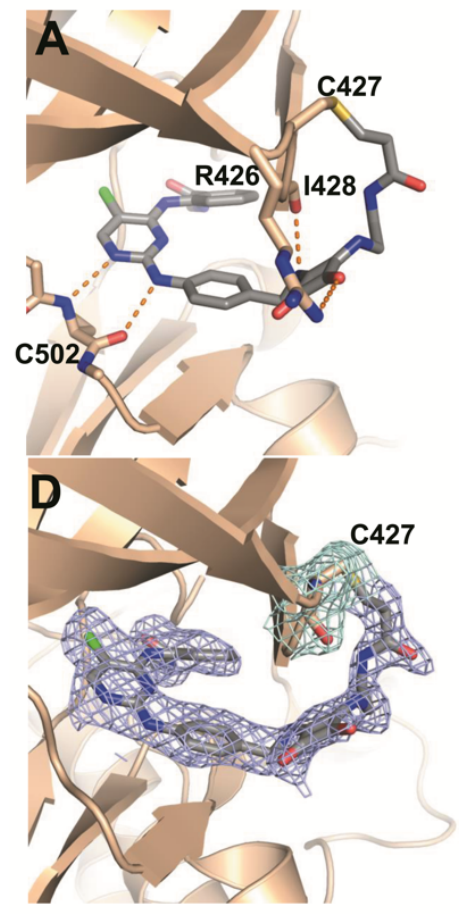

5

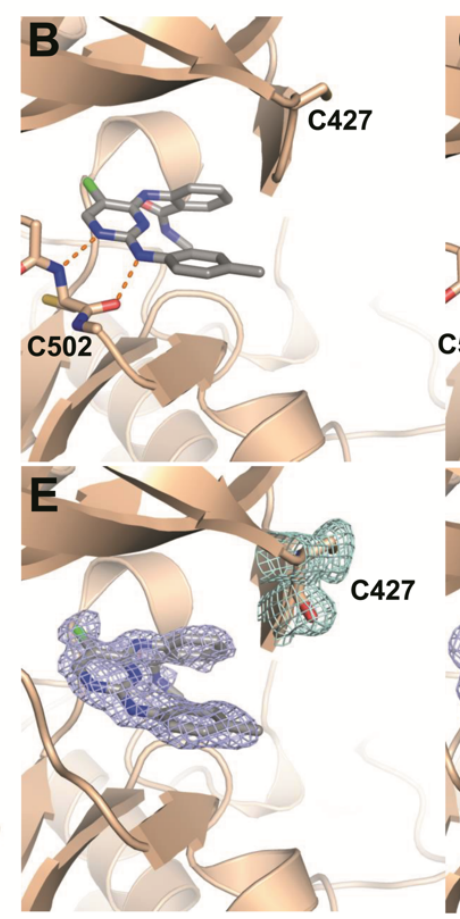

6

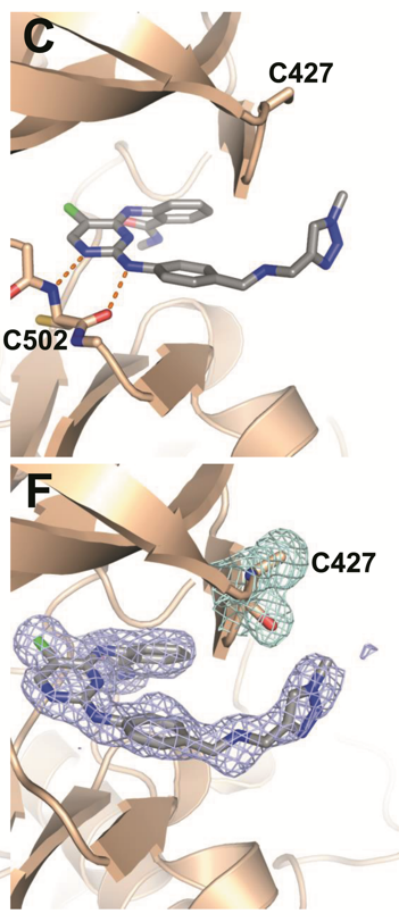

7

Figure 4. Crystal structures of the FAK kinase domain in complex with inhibitors 5 (PDB ID: 6GCX), 6 (PDB ID: 6GCW) and 7 (PDB ID: 6GCR). (A-C) The active site of the FAK kinase domain bound 5, 6 and 7 are shown. Inhibitors are shown in grey for ordered regions and white for disordered regions. Although the white regions are modeled, they are not supported by electron density as can be seen in panels A-C. Key hydrogen bonds between the compounds and the FAK kinase are shown as orange dashed lines. (D-F) 2Fo-Fc electron density countered a $1 \sigma$ is shown for the compounds (blue mesh) and Cys427 (cyan mesh), which are shown in stick representation. The FAK kinase is shown as ribbon in tan. Note that only compound 5 exhibits continuous density connecting to Cys 427.

Interestingly, for $\mathbf{5}$, it is observed that two hydrogen bonds are formed between the side chain nitrogen of Arg426 and the carbonyl of the squarate, and the CO of Ile428 forms a hydrogen bond with the NH of the squaramide attached to the benzylamino moiety (Figure 5). On the contrary, 1,2,3-triazole group can not make this type of the interaction (Figure 5), supporting that the binding of the squarate group to the FAK active site is crucial to guide the electrophilic group of 5 for reaction with the nucleophilic thiol group of Cys427 (Figure 4A). 
Furthermore, only the cocrystal structure with $\mathbf{5}$ revealed a strong and continuous electron density between C427 and the electrophilic carbon in 5 (Figure 4D) and thus clearly confirmed a covalent bond formation.

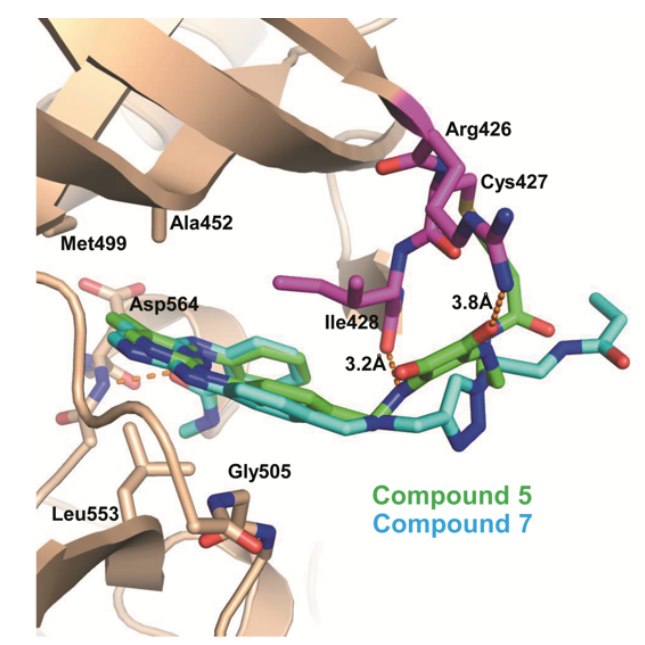

Figure 5. Superposition of the two structures of compounds 5 and 7 bound to FAK. The compounds 5 (green), 7 (blue) and side chains in FAK interacting with the compound are shown in stick representation. Hydrogen bonds are shown as orange dashed lines.

Anti-proliferation activity of compound 5 in SCC cells. Having established the potency and irreversibility of inhibitor $\mathbf{5}$ binding to the FAK active site in vitro, we investigated the inhibition of the full-length FAK kinase by $\mathbf{5}$ in squamous cell carcinoma (SCC) cells, which were induced in K14CreER FAK floxflox mice using a two stage chemical skin carcinogenesis assay as previously described. ${ }^{20}$ In a previous study, we have demonstrated that PF-562,271, a reversible inhibitor of FAK kinase was able to block the 3D proliferation of the SCC cells, cause squamous cell carcinoma regression and inhibit tumor growth in vivo. ${ }^{21}$ The anti-proliferation of the irreversible inhibitor 5 against SCC cells was first assessed using cell nuclei counts, and VS-4718, a highly potent reversible inhibitor of FAK which is under clinical development, ${ }^{22}$ was used as a control. Treatment of SCC FAKWT cells with 5 resulted in a dose-dependent inhibition of proliferation with similar $\mathrm{ED}_{50}$ $(1.73 \pm 0.1 \mu \mathrm{M})$ as that of VS-4718 $(1.49 \pm 0.2 \mu \mathrm{M})($ Figure $\mathrm{S} 3)$.

Covalent inhibition of FAK by compound 5 in SCC cells. We tested the inhibition of FAK autophosphorylation in SCC cell line with the irreversible inhibitor 5. As shown in Figure 6a, compound 5 blocked Tyr397 phosphorylation in a dose-dependent manner and FAK autophosphorylation was significantly inhibited at low concentrations in these cancer 
cell lines, which is comparable to VS-4718. It is also consistent with its inhibitory activity shown against the FAK kinase, suggesting that this compound is able to effectively inhibit cellular FAK autophosphorylation and phosphorylation of kinase targets at low concentrations. Then, we examined the reversibility of the autophosphorylation of Tyr397 of FAK by performing washout experiments. Upon washout, VS-4718 lost its inhibition capacity against FAK, which is coherent with its reversible property. In contrast, $\mathbf{5}$ retained potent inhibition of FAK after washing out the inhibitor, and demonstrated covalent binding (Figure 6d).

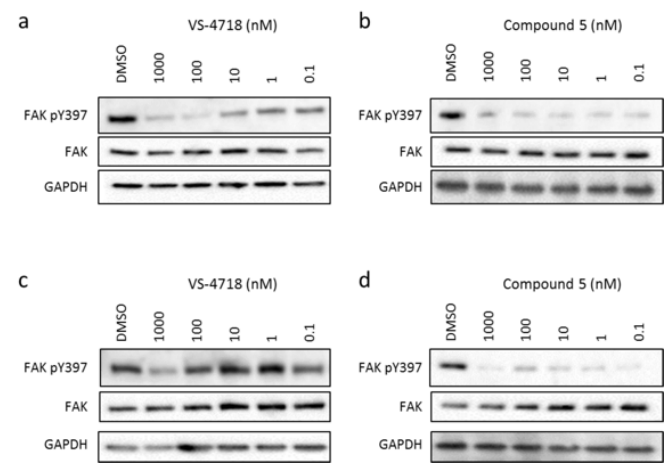

Figure 6. Inhibition of FAK autophosphorylation in SCC cells. (a-b) 5 and VS-4718 inhibited the autophosphorylation of FAK in a dose-dependent manner; (c-d) Washout experiments showed that the inhibition of FAK autophosphorylation could be reversed for the reversible inhibitor VS-4718, but not for the irreversible inhibitor 5. The experiments were repeated three times and were consistent.

Kinase Selectivity Profile of Covalent Inhibitor 5. In order to investigate the selectivity of the irreversible inhibitor $\mathbf{5}$, we tested this compound in vitro against a panel of ten kinases (EGFR, HER2/ERBB2, IGF1R, c-Kit, PDGFR, Pyk2, c-Src, IRR, and IR) determined by Eurofins Pharma Discovery Services, Poitiers, France to investigate its selectivity (Table S1, Supporting Information). A TR-FRET based kinase protocol was used with human recombinant protein in the presence of $1 \mu \mathrm{M}$ of compound $\mathbf{5}$. Interestingly, this compound showed only $21 \%$ inhibition on the IR (insulin receptor) kinase even at the high concentration of $1 \mu \mathrm{M}$. This is in contrast to TAE226, which exhibited high potency towards IR $\left(\mathrm{IC}_{50}=26 \mathrm{nM}\right) \cdot{ }^{19}$ Even if TAE226 has displayed a potent antitumor effect both in vitro and in vivo in a large variety of cancers such as brain tumors, ${ }^{23}$ esophageal cancer, ${ }^{24}$ breast cancer, ${ }^{25}$ ovarian cancer, ${ }^{26}$ and gastrointestinal stroma tumor, ${ }^{27}$ TAE226 never entered in clinic studies, because this compound inhibited the insulin receptor with a high potency and showed important side effects in animal studies. ${ }^{19}$ 


\section{CONCLUSIONS}

In summary, we described the first irreversible sub-nanomolar inhibitor of FAK containing a pyridimine scaffold and a Michael acceptor as electrophile up to date through structure-based and medicinal chemistry optimization. The crystal structure of the FAK kinase domain in complex with this inhibitor was resolved to display the formation of a covalent bond. Beyond generating and characterizing the covalent FAK inhibitor, our approach can direct the design of new electrophilic inhibitors which target a noncatalytic cysteine in proteins. The irreversible inhibitor $\mathbf{5}$ showed a highly potent decrease of autophosphorylation of FAK in SCC cells, suggesting that this compound could efficiently block this key event of the FAK signaling pathway which initiates most effects of this kinase. It is worth noting that $\mathbf{5}$ exhibited an anti-proliferative effect in SCC cells similar to that of VS-4718, which is currently under phase I studies. Moreover, this compound displayed low inhibition against the IR (insulin receptor) kinase, which might provide a new mode of action and overcome the side effects observed with TAE226. Further studies into molecular mechanisms of this type of compounds against cancer including anti-proliferation of human cancer cells and the regulation of tumorigenesis and metastatic progression is underway in the laboratory to demonstrate the advantages for the development of novel cancer therapies.

\section{METHODS}

Chemistry. Methods for the synthesis of compounds, characterization, and spectra are described in detail in the Supporting Information.

Enzyme Inhibition Studies. Inhibitory potency in a FAK enzymatic assay was determined using an $\mathrm{ADP}-\mathrm{Glo}^{\mathrm{TM}}$ kinase assay. Briefly, $4 \mu \mathrm{L}$ of assay mixture containing 0.5 $\mu \mathrm{g}$ FAK substrate, $5 \mathrm{ng}$ FAK, $8 \mu \mathrm{M}$ ATP and $1 \mu \mathrm{L}$ of compounds at desired concentrations in Kinase reaction buffer ( $40 \mathrm{mM}$ Tris, $20 \mathrm{mM} \mathrm{MgCl}, 0.1 \mathrm{mg} / \mathrm{mL}$ BSA, $2 \mathrm{mM} \mathrm{MnCl} 2,2 \mu \mathrm{M}$ DTT) was added into a 384-well plate. After incubation at $37{ }^{\circ} \mathrm{C}$ for $1 \mathrm{~h}$, the kinase reaction was stopped by the addition of $5 \mu \mathrm{L}$ of ADP-Glo ${ }^{\mathrm{TM}}$ Reagent to deplete the unconsumed ATP and leave only ADP. The plate was incubated at room temperature for $40 \mathrm{~min}$, and added by $10 \mu \mathrm{L}$ of Kinase Detection Reagent to convert ADP to ATP and introduce luciferase and luciferin to detect ATP. After incubation at room temperature for 15-20 minutes, the luminescence signal was detected with an Enspire plate reader. The $\mathrm{IC}_{50}$ value was determined for each compound, from a sigmoid dose-response curve using Graph-Pad Prism (GraphPad Software, San Diego, CA, USA). 
Inhibition of FAK Autophosphorylation in SCC cells. SCC FAK-WT cells were cultured in Glasgow Minimum Essential Medium (10\% foetal calf serum, $2 \mathrm{mM}$ 1-glutamine, NEAA, sodium pyruvate and MEM vitamins). Cells were seeded in 6 well plates at 100,000 cells per well. Compounds were made up in DMSO to 1000x final concentration and 24 hours after cell seeding were added to the culture media resulting in a final DMSO concentration of $0.1 \%$. Compounds were incubated on cells for $48 \mathrm{~h}$ before cell lysis. For wash out experiments, cells were washed with PBS twice and fresh media was added for 3 hours.

For cell lysis, briefly, wells were washed in ice-cold PBS, drained and cells lysed in MD Anderson buffer (1\% Triton X 100, $50 \mathrm{mM}$ Hepes $\mathrm{pH} 7.4,150 \mathrm{~m} \mathrm{M} \mathrm{NaCl}, 1.5 \mathrm{mM} \mathrm{MgCl} 2$ and $1 \mathrm{mM}$ EGTA) supplemented with a protease and phosphatase tablet (Sigma-Aldrich). Cell lysates were clarified by centrifugation at $12,000 \mathrm{x} \mathrm{g}$ for 10 minutes and the protein concentration determined by Bradford assay (Thermo Fisher Scientific). $20 \mu \mathrm{g}$ protein of each lysate was resolved using 4-15\% polyacrylamide gels (Bio-Rad) and transferred to PVDF membranes, blocked and probed with primary antibodies overnight. Blots were washed in TBS/0.1\% Tween and incubated with anti-rabbit conjugated horseradish peroxidase. Blots were washed in TBS/ $0.1 \%$ Tween and visualised with BM Chemiluminescence Western Blotting Substrate (Sigma-Aldrich) on a Bio-Rad ChemiDocimager. Blot densitometry was determined using Image Lab software (Bio-Rad).

Crystallization and Structure Determination. The kinase domain of the avian FAK protein (FAK411-686) was expressed and purified following a previously described assay. ${ }^{28}$ The inhibitor-FAK complex was formed by incubation of the compound (final concentration $10 \mathrm{mM})$ with the protein $(8 \mathrm{mg} / \mathrm{mL})$ at $4{ }^{\circ} \mathrm{C}$ overnight. Crystals of the complex were grown, mixing an equal volume of the complex with the crystallization condition (100 mM Tris, $\mathrm{pH}$ 8.5, $100 \mathrm{mM} \mathrm{Li}_{2} \mathrm{SO}_{4}, 20-24 \%$ PEG4000, $10 \mathrm{mM}$ TCEP). Crystals were cryoprotected by a quick soak into the following cryosolution $100 \mathrm{mM}$ Tris $\mathrm{pH} 8.5,100 \mathrm{mM} \mathrm{Li}_{2} \mathrm{SO}_{4}, 24 \%$ PEG4000, $10 \mathrm{mM}$ TCEP, 35\% ethylene glycol and then flash-frozen. Diffraction data were collected at synchrotron facilities in beamline ID30-1 at ESRF (Grenoble, France) (compounds 5, 7) or the XALOC beamline at ALBA (compound 6) and processed with XDS. ${ }^{29}$ To provide an initial set of phases, the molecular replacement protocol in Phaser was used using the FAK kinase model from PDB 2 JKK. ${ }^{30}$ Refinement was carried out using the program Refmac and manual rebuilding was performed with $\operatorname{Coot}^{31-32}$ The Dundee PRODRG2 Server was used to create the initial model for inhibitors 5, 7 and 10.33 Final R- 
factors are 22.3/26.2 (Rwork/Rfree) for FAK/5, 19.5/22.3 for FAK/6 and 21.7/27.4 for $\mathrm{FAK} / 7$.

\section{ASSOCIATED CONTENT}

Supporting Information

The Supporting Information is available free of charge on the ACS Publications website at DOI: ....

Additional figures, experimental methods and analyses (PDF)

\section{Accession Codes}

The structures of FAK domain bound to compounds 5, 6 and 7 have been deposited in the Protein Data Bank with PDB accession codes 6GCX, 6GCW and 6GCR, respectively.

\section{AUTHOR INFORMATION}

Corresponding Author

†E-mail: huixiong.chen@parisdescartes.fr

Author Contributions

$\$$ These authors contributed equally.

\section{Notes}

The authors declare no competing financial interest.

\section{ACKNOWLEDGMENTS}

We thank the ESRF and ALBA synchrotron facilities for providing access to their facilities and the staff for their assistance in the data collection. D. Lietha was supported by the Spanish Ministry of Economy, Industry and Competitiveness (MEIC) Grant MEIC Project Retos BFU2016-77665-R co-funded by the European Regional Development Fund (ERDF) and the Worldwide Cancer Research (15-1177). B. Li thanks China Scholarship Council (CSC) for financial support.

\section{REFERENCES}


(1) Schober, M., Fuchs, E. (2011) Tumor-initiating stem cells of squamous cell carcinomas and their control by TGF- $\beta$ and integrin/focal adhesion kinase (FAK) signaling. Proc Natl Acad Sci U S A., 108, 10544-10549.

(2) Serrels, A., Canel, M., Brunton, VG., Frame, M. C. (2011) Src/FAK-mediated regulation of Ecadherin as a mechanism for controlling collective cell movement: insights from in vivo imaging. Cell Adh Migr., 5, 360-365.

(3) Golubovskaya, V. M. (2014) Targeting FAK in human cancer: from finding to first clinical trials. Front. Biosci Landmark Ed., 19, 687-706.

(4) Golubovskaya, V.M. (2010) Focal adhesion kinase as a cancer therapy target. Anticancer Agents Med Chem., 10, 735-741.

(5) Yoon, H., Dehart, J. P, Murphy, J. M, Lim, S-T. S. (2015) Understanding the roles of FAK in cancer: inhibitors, genetic models, and new insights. J. Histochem Cytochem., 63, 114-128.

(6) Shanthi, E., Krishna, M. H, Arunesh, G. M., Venkateswara, Reddy K., Sooriya, Kumar J.,Viswanadhan, V. N. (2014) Focal adhesion kinase inhibitors in the treatment of metastatic cancer: a patent review. Expert Opin Ther Pat., 24, 1077-1100.

(7) Jones, S. F., Siu, L. L, Bendell, J. C., Cleary, J. M, Razak, A. R. A., Infante, J. R., Pandya, S. S., Bedard, P. L., Pierce, K. J., Houk, B., Roberts, W. G., Shreeve, S. M., Shapiro, G. I. (2015) A phase I study of VS-6063, a second-generation focal adhesion kinase inhibitor, in patients with advanced solid tumors. Invest New Drugs, 33, 1100-1107.

(8) Roy-Luzarraga, M., Hodivala-Dilke, K. (2016) Molecular Pathways: Endothelial Cell FAK-A Target for Cancer Treatment. Clin Cancer Res., 22, 3718-3724.

(9) Lim, S. T., Miller, N. L., Chen, X. L., Tancioni, I., Walsh, C. T., Lawson, C., Uryu, S., Weis, S. M., Cheresh, D. A., Schlaepfer, D. D. (2012) Nuclear-localized focal adhesion kinase regulates inflammatory VCAM-1 expression. J Cell Biol., 197(7), 907-919.

(10) Serrels, A., Lund, T., Serrels, B., Byron, A., McPherson, R. C., Kriegsheim, A. V., GómezCuadrado, L. G., Canel, M., Muir M., Ring J. E., Maniati, E., Sims, A. H., Pachter, J. A., Brunton, V. G., Gilbert, N., Anderton, S. M., Nibbs, R. J. B, Frame1 M. C. (2015) Nuclear FAK controls chemokine transcription, Tregs, and evasion of anti-tumor immunity. Cell, 163(1), 160-73.

(11) Sanderson, K. (2013) Irreversible kinase inhibitors gain traction. Nat. Rev. Drug Discovery, 12, 649-651;

(12) Singh, J., Petter, R. C., Baillie, T. A., Whitty, A. (2011) The resurgence of covalent drugs. Nat. Rev. Drug Discovery, 10, 307-317.

(13) Barf, T., Kaptein, A. (2012) Irreversible protein kinase inhibitors: balancing the benefits and risks. J. Med. Chem., 55 (14), 6243-6262.

(14) Lietha, D., Eck, M. J. (2008) Crystal structures of the FAK kinase in complex with TAE226 and related bis-anilino pyrimidine inhibitors reveal a helical DFG conformation. PLoS One, 3, e3800. 
(15) Dao, P., Jarray, R., Smith, N., Lepelletier, Y., Le Coq, J., Lietha, D., Hadj-Slimane, R., Herbeuval, J. P., Garbay, C., Raynaud, F., Chen, H. (2014) Inhibition of both focal adhesion kinase and fibroblast growth factor receptor 2 pathways induces anti-tumor and anti-angiogenic activities. Cancer Letters, 348, 88-99.

(16) Luzzio, M. J., Kath, J. C. Pyrimidine derivatives for the treatment of abnormal cell growth. $\mathrm{WO} / 2005 / 111024$.

(17) Imbach, P., Kawahara, E., Konishi, K., Matsuura, N., Miyake, T., Ohmori, O., Roesel, J., Teno, N., Umemura, I. Pyrimidine derivatives. WO/2006/021454.

(18) Sapountzis, I., Betzemeier, B., Stadtmueller, H. 2,4-diaminopyrimidine derivates as ptk2inhibitors for the treatment of abnormal cell growth. WO/2010/055117.

(19) Liu, T. J., LaFortune, T., Honda, T., Ohmori, O., Hatakeyama, S., Meyer, T., Jackson, D., de Groot, J., Yung, W. K. A. (2007) Inhibition of both focal adhesion kinase and insulin-like growth factor-I receptor kinase suppresses glioma proliferation in vitro and in vivo. Mol. Cancer Ther., 6, $1357-1367$.

(20) McLean, G. W., Komiyama, N. H., Serrels, B., Asano, H., Reynolds, L., Conti, F., HodivalaDilke, K., Metzger, D., Chambon, P., Grant, S. G., Frame, M. C. (2004) Specific deletion of focal adhesion kinase suppresses tumor formation and blocks malignant progression. Genes Dev., 18, 2998-3003.

(21) Serrels, A., McLeod, K., Canel, M., Kinnaird, A., Graham, K., Frame, M. C., Brunton V. G. (2012) The role of focal adhesion kinase catalytic activity on the proliferation and migration of squamous cell carcinoma cells. Int. J. Cancer. 131(2), 287-97.

(22) Shapiro, I. M., Kolev, V. N., Vidal, C. M., Kadariya, Y., Ring, J. E., Wright, Q., Weaver, D. T., Menges, C., Padval, M., McClatchey, A. I., Xu, Q., Testa, J. R., Pachter, J. A. (2014) Merlin deficiency predicts FAK inhibitor sensitivity: a synthetic lethal relationship. Sci Transl Med., 6(237), $237 \mathrm{ra} 68$.

(23) Shi, Q., Hjelmeland, A. B., Keir, S. T., Song, L., Wickman, S., Jackson, D., Ohmori, O., Bigner, D. D., Friedman, H. S., Rich, J. N. (2007) A novel low-molecular weight inhibitor of focal adhesion kinase, TAE226, inhibits glioma growth. Mol. Carcinog., 46, 488-496.

(24) Watanabe, N., Takaoka, M., Sakurama, K., Tomono, Y., Hatakeyama, S., Ohmori, O., Motoki, T., Shirakawa, Y., Yamatsuji, T., Haisa, M., Matsuoka, J., Beer, D. G., Nagatsuka, H., Tanaka, N., Naomoto, Y. (2008) Dual tyrosine kinase inhibitor for focal adhesion kinase and insulin-like growth factor-I receptor exhibits anticancer effect in esophageal adenocarcinoma in vitro and in vivo. Clin. Cancer Res., 14, 4631-4639.

(25) Kurio, N., Shimo, T., Fukazawa, T., Takaoka, M., Okui, T., Hassan, N. M. M., Honami, T., Hatakeyama, S., Ikeda, M. Naomoto, Y., Sasaki, A. (2011) Anti-tumor effect in human breast 
cancer by TAE226, a dual inhibitor for FAK and IGF-IR in vitro and in vivo. Exp. Cell Res., 317, $1134-1146$.

(26) Halder, J., Lin, Y. G., Merritt, W. M., Spannuth, W. A., Nick, A. M., Honda, T., Kamat, A. A., Han, L. Y., Kim, T. J., Lu, C., Tari, A. M., Bornmann, W., Fernandez, A., Lopez-Berestein, G., Sood, A. K. (2007) Therapeutic efficacy of a novel focal adhesion kinase inhibitor TAE226 in ovarian carcinoma. Cancer Res., 67, 10976-10983.

(27) Sakurama, K., Noma, K., Takaoka, M., Tomono, Y., Watanabe, N., Hatakeyama, S., Ohmori, O., Hirota, S., Motoki, T., Shirakawa, Y., Yamatsuji, T., Haisa, M., Matsuoka, J., Tanaka, N., Naomoto, Y. (2009) Inhibition of focal adhesion kinase as a potential therapeutic strategy for imatinib-resistant gastrointestinal stromal tumor. Mol. Cancer Ther., 8, 127-134.

(28) Dao, P., Jarray, R., Le Coq, J., Lietha, D., Loukaci, A., Lepelletier, Y., Hadj-Slimane, R., Garbay, C., Raynaud, F., Chen, H. (2013) Synthesis of novel diarylamino-1,3,5-triazine derivatives as FAK inhibitors with anti-angiogenic activity. Bioorg. Med. Chem. Lett. 23, 4552-4556.

(29) Kabsch, W. (2010) XDS. Acta Crystallogr. D Biol. Crystallogr. 66, 125-132.

(30) McCoy, A.J., Grosse-Kunstleve, R. W., Adams, P. D., Winn, M. D., Storoni, L. C., Read, R. J. (2007) Phaser crystallographic softwar. J. Appl. Crystallogr. 40 658-674.

(31) Murshudov, G.N., Vagin, A. A., Dodson, E. J. (1997) Refinement of macromolecular structures by the maximum-likelihood method. Acta Crystallogr. D Biol. Crystallogr. 53 240-255.

(32) Emsley, P., Cowtan, K. (2004) Coot: model-building tools for molecular graphics. Acta Crystallogr. D Biol. Crystallogr. 60, 2126-2132. 